\title{
From the Editor
}

\section{Watching the leaves turn}

\section{"Autumn shows us how beautiful it is to let things go." - Unknown}

Brilliant scarlet red, orange russet, blazing yellow, autumn pine green and earth brown leaves color the trees as I write this From the Editor. It's a three-day holiday weekend where we are enjoying the peak of colorful fall foliage in New Hampshire. As Lee Maynard wrote, "I loved autumn, the season of the year that God seemed to have put there just for the beauty of it."

Today is October 8, 2021 and Indigenous Peoples' Day in the United States. It was recently proclaimed a national holiday honoring the history and culture of the American Indigenous peoples. If you would like to learn more about the importance of this holiday, I encourage you to read: https://www.whitehouse.gov/briefingroom/presidential-actions/2021/10/08/a-proclamation-indigenous-peoples-day-2021/

To recognize this holiday, I include the following land acknowledgement:

"We gratefully acknowledge the Native Peoples on whose ancestral homelands we gather, as well as the diverse and vibrant Native communities who make their home here today." NMAI Land Acknowledgement

This issue of WORK has 31 articles. It begins with an important paper, Mapping the occupational therapy workforce research worldwide: Study protocol for a scoping review, authored by Jesus, von Zweck, Mani, Kamalakannan, Bhattacharjya and Ledgerd. The issue continues with articles on topics such the impact of COVID-19, teleworking, emotional burnout, e-learning, well-being, an introduction to the Industrial Town's Safety Management (ITSM) system, developing a safety audit, cargo handling, noise control methods, and a scoping review of integrative prevention and coordinated action toward primary, secondary and tertiary prevention in workplaces among other topics.

Our first 2022 Learn at WORK webinar is on Wednesday, January 26, 2022 at 1pm-2pm EST by Dr. Bhibha M. Das on her article published in WORK titled, Nurses' physical activity exploratory study: Caring for you so you can care for others. You can register at: https://attendee.gotowebinar.com/register/2817144919007435277

Please stay up-to-date on our Learn at WORK webinars, blogs and news by going to our website at workjournal.org

As started this From the Editor about fall, I thought I would conclude it with:

"Everyone must take time to sit and watch the leaves turn." Elizabeth Lawrence

With kind regards,

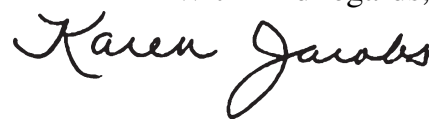

Founding Editor, WORK Occupational therapist \& ergonomist

Kjacobs@bu.edu workjournal.org blogs.bu.edu/kjacobs/ 